\title{
A new species of Gekko found in Yakushima, one of the small island south of Kyushu.
}

\author{
by
}

Takaji Matsui* and Yaichiro Okada**

\section{Gekko yakuensis n. sp. (Figs. 1,2)}

Type specimen: adult female JSC*** \#522

Type Locality: Anbo, Yakushima Island, Kagoshima Prefecture, Japan, collected on May 30, 1963.

Description: Head large, subtrianguler in outline, rostral squarish, about twice as wide as high, bounded above by two small supranasals, and one small scale between supranasals; nostril surrounded by first supralabial, two postnasals, and supranasal; distance between nostril and eye nearly equal to the distance between eye and ear-opening; eye large, its diameter more than half the distance between eye and tip of snout; ear-opening small, somewhat slit-like; 12 or 13 supralabials; 9 or 10 infralabials; mental pentagonal, somewhat large, scarcely larger than the adjacent infralabials; four somewhat enlarged chinshields on either side of jaw bordering lower labials; the two in contact with mental and with each other are longer than broad; behind these several polygonal smaller shields; head covered above with granules, those above labials rather elongate; body covered above with small granules and somewhat larger roundish, conical tubercles; a slight skin fold from axilla to groin; innerdigit with 10 lamellae, second with 10, third with 12 , fourth with 12 , fifth with 11 ; forelimbs somewhat larger and longer, toes broader towards tip than at base and tip; ten to fifteen broad undivided lamellae on underside of toes; first and second toes with 10 ; third with 13 ; fourth with 15 ; fifth with 14 ; lower surface of body except throat, covered with somewhat larger inbricate scales; tail gradually tapering, not swollen at base, pointed at end, more than twenty somewhat deep transverse grooves on tail, each with transverse rows of scales; transverse row of scales on each annulation more regular than others; below, scales larger than above, the median paired series largest; three rows to each annulation; one large tubercle on each side of base of tail.

Color in life: Dorsal side of trunk dark gray, with dark black irregular transverse bands, belly with dark black spots; upperside of tail dark gray, with dark black irregular transverse bands, underside light gray with many dark brown spots.

\begin{tabular}{|c|c|c|c|c|}
\hline \multicolumn{5}{|l|}{ Measurements (in mm): } \\
\hline Museum & JSC & JSC & JSC & JSC \\
\hline Number & $\$ 520$ & $\$ 521$ & $\# 522$ & $\$ 523$ \\
\hline Locality & Miyanoura & Miyanoura & Anbo & Miyanoura \\
\hline \multirow[t]{2}{*}{ Date } & $25 / ' 64$ & $25 / ’ 64$ & $30 / ' 63$ & 1963 \\
\hline & VII & VII & V & \\
\hline Collector & M. Ikeda & M. Ikeda & M. Matsui & M. Ikeda \\
\hline Sex & $\hat{o}$ & ㅇ & ㅇ & $\hat{\delta}$ \\
\hline Total length & $98+$ & 106 & $114+$ & 135 \\
\hline Snout to vent & 47 & 50 & 70 & 66 \\
\hline Vent to tip of tail & $51+$ & 56 & $44+$ & 69 \\
\hline Snout to ear-opening & 12 & 12 & 17 & 18 \\
\hline Snout to anterior border of eye & 6 & 6 & 8 & 6 \\
\hline
\end{tabular}


Diameter of eye

Ear-opening to posterior border of eye

Snout to groin

Axilla to groin

Greatest width of body

Greatest width of head

Length of head

Forelimb, from axilla

Hindlimb, from groin

Longest toe

Supralabials

Infralabials

Femoral pores

\section{4}

4.2

22

21

10

10

8

14

23

5

12

13

5
3.2

4

23

21

10

10.5

8.5

14

24

5.2

12

12
5

6

31

27

12

14

11

21

34

5

12

11

6

Remarks: When the Kyoto Heian High school conducted its biological survey of Yakushima, one of the members of the team noted the presence a large Gekko different from the common Gekko Japonicus (DUMERIL et BIBRON). In 1963, one of the authors, T. Matsui, surveyed Yakushima Island and collected one female and observed several other individuals in a forest at $100-150 \mathrm{~m}$ above sealevel, along the sea coast. Also he obtained 3 alcoholic preserved specimens from Moriaki Ikeda, Yakushima High School.

The present species somewhat resembles Gekko tawaensis Okada in outline but differs from it by the presence of 250-300 granulated minute scales on the head and trunk and a scattering of distinct large conical scales. The dorsal surface of tail is covered with minute, homogeneosus scales and with 20 or more somewhat deep transverse grooves; the median two scales of the grooves are larger than the others, and are intermingled with a few small scales.

The present new species also differs from Gekko japonicus in size of body, which is usually bigger than that of japonicus measuring $66.70 \mathrm{~mm}$ or more.

The present species is always found in the forest away from populated areas. It seems to have a different territory than Gekko japonicus.

\footnotetext{
* Japan Snake Center. ** Tokai University. *** Japan Snake Center.
} 


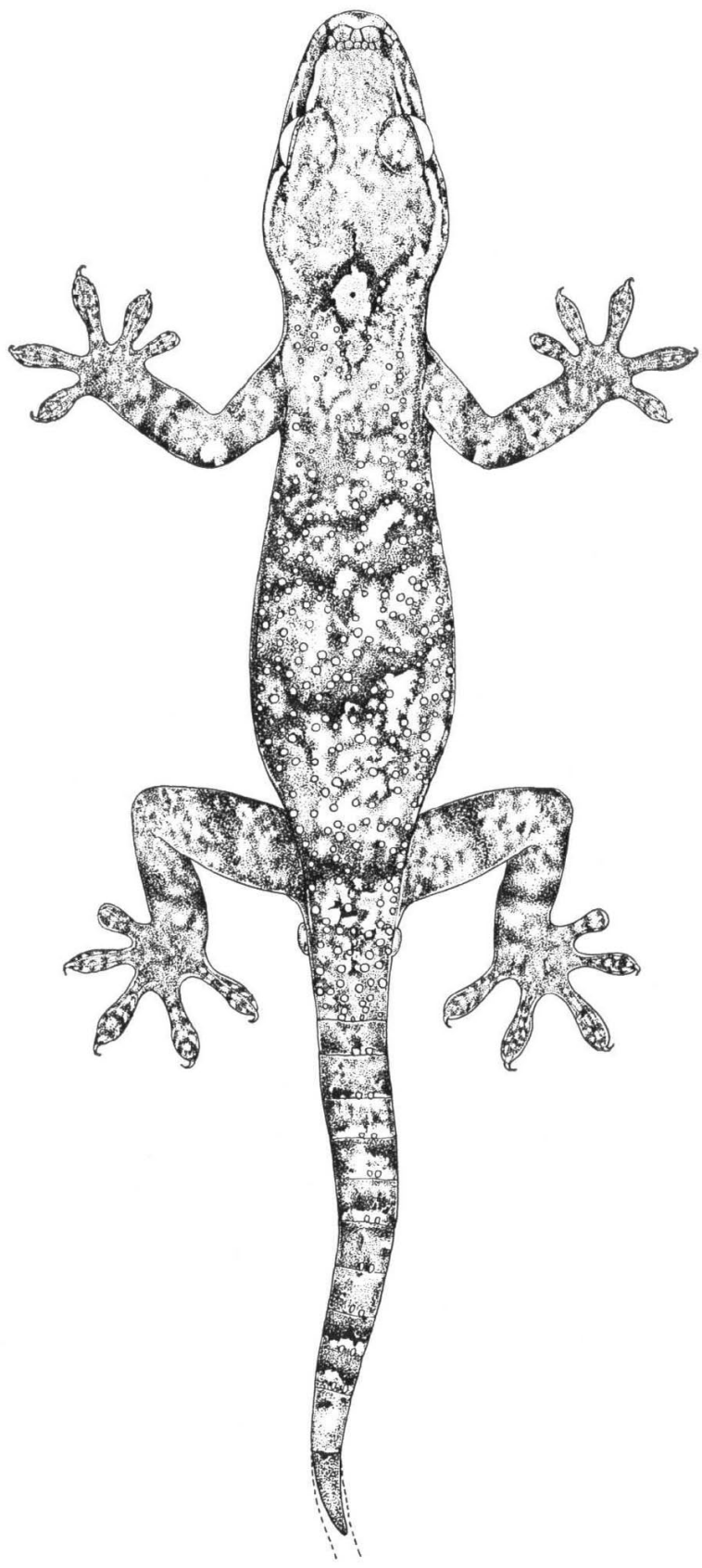

Fig. 1. Gekko yakuensis n. sp. 


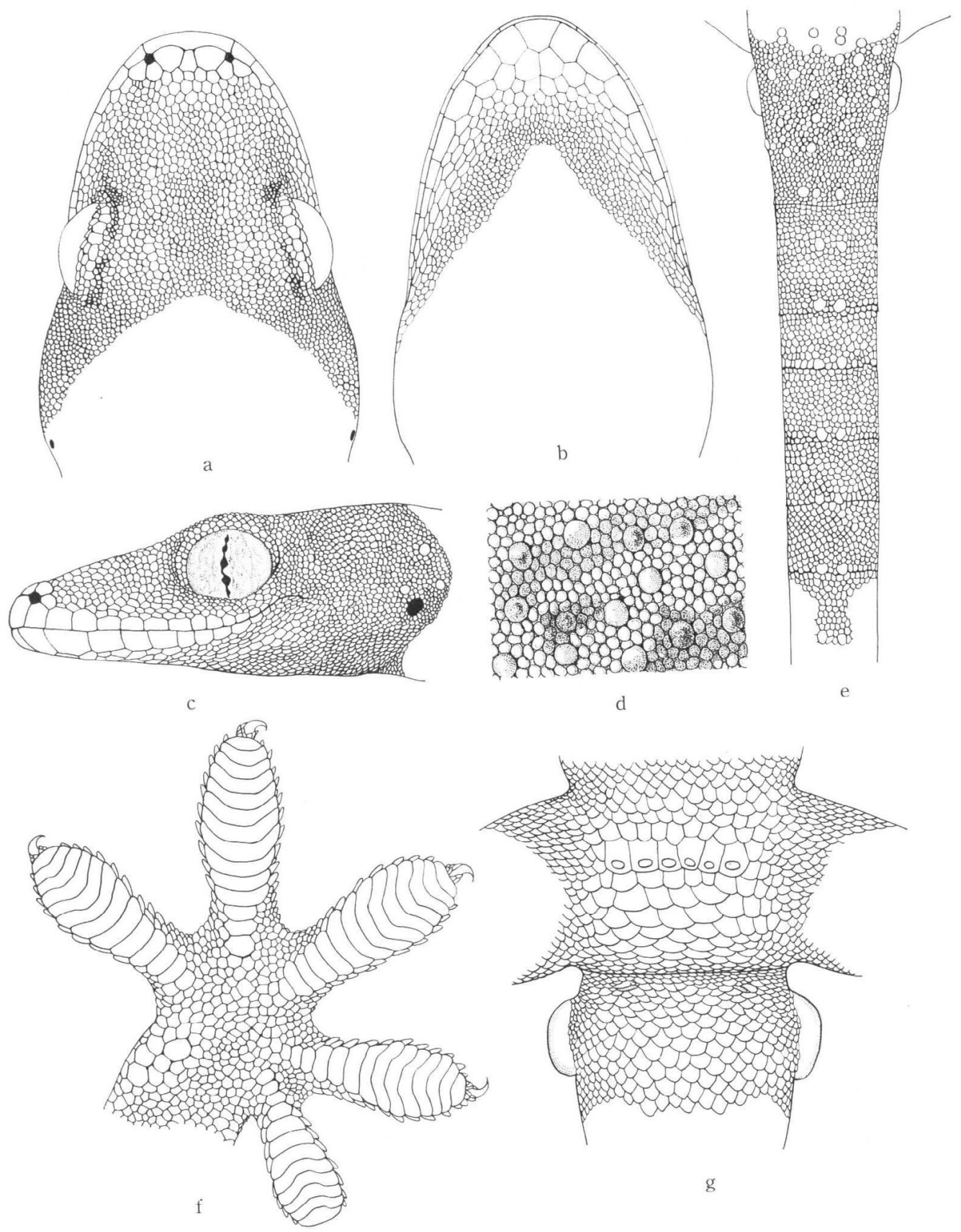

Fig. 2. Gekko yakuensis n. sp. from Anbō, Yakushima, Kagoshima prefecture, Kyushu.
a. Dorsal view of head
b. Ventral view of head
c. Lateral view of head
d. A piece of dorsal scales
e. Dorsal view of tail
f. Underside of hand
g. Underside of anal region 